\title{
Pensando e avaliando propostas interativas a distância no Ensino Superior
}

\author{
Luciane Corte Real ${ }^{1}$, Rafaela Machado ${ }^{2}$ \\ Faculdade de Educação - Universidade Federal do Rio Grande do Sul (UFRGS) ${ }^{1}$ \\ Universidade Federal do Rio Grande do Sul (UFRGS) ${ }^{2}$ \\ (luciane.real@ufrgs.br ${ }^{1}$; rafaa.machado@hotmail.com ${ }^{2)}$
}

\begin{abstract}
Resumo: $O$ presente artigo é um recorte de uma pesquisa na Universidade $X$ sobre Apropriações Discentes em Ambientes Virtuais de Aprendizagem. Trata-se de uma pesquisa qualitativa na forma de estudo de caso onde foram acompanhadas as presenças de ensino, social e cognitivas (modelo de Garrison et al, 2000) em fóruns de discussão. A análise apontou para a importância da categoria presença cognitiva e social juntas para uma aprendizagem significativa, pois se articula as construções teóricas com as experiências dos alunos.
\end{abstract}

Palavras-chave: Educação a Distância, práticas pedagógicas, fórum de discussão, aprendizagem.

Abstract: This article is a part of a research in University $X$ on Appropriations Learners in Virtual Learning Environments. This is a qualitative research in the form of a case study where they were accompanied by the presences of teaching, social and cognitive (model Garrison et al, 2000) in discussion forums. The analysis pointed to the importance of the category cognitive and social presence together for meaningful learning because it articulates the theoretical constructs from the experiences of students.

Keywords: Distance Education, pedagogical practices, discussion forum, learning.

\section{Apresentação}

A partir do entendimento de que a aprendizagem se dá na interação com o objeto de conhecimento é necessário propostas interativas na Educação e principalmente na Educação a Distância (EAD), pois nas possibilidades de interações se torna possível avaliar as aprendizagens dos alunos. É pontuado a importância de avaliar as interações em EAD para que se aprimore as práticas pedagógicas neste campo. 
A interação pode ser o foco das disciplinas EAD a partir do pensamento que o uso das tecnologias apresenta mudanças em práticas culturais ao modificar a forma como as pessoas aprendem, colaboram, partilham e se desenvolvem.

Real e Picetti (2012) afirmam que entre as diferentes formas de interação nos Ambientes Virtuais de Aprendizagem, o fórum de discussão pode ser um espaço de intenso debate e de possibilidades de construção de conhecimentos. $\mathrm{O}$ fórum pode se tornar um espaço de encontro entre os alunos e professores possibilitando diferentes formas de analisar e refletir, podendo constituir-se assim, como um espaço de aceitação dos diversos pensamentos e de diferentes níveis de aprendizagem.

Longhi et al (2009) estudam a subjetividade afetiva em registros efetuados no fórum de Ambientes Virtuais de Aprendizagem. Já Bassani (2009) investiga a dinâmica da conversação em um fórum de discussão, a fim de compreender os processos que envolvem a formação de comunidades virtuais de aprendizagem. A investigação aqui apresentada trata de refletir sobre as presenças de ensino, social e cognitiva presentes nos fóruns de discussão de uma disciplina semipresencial com o objetivo de avaliar as possibilidades de aprendizagem dos alunos nestes espaços.

\section{Estratégia metodológica}

Trata-se de um recorte de uma pesquisa qualitativa iniciada em 2010 na Universidade Federal do Rio Grande do Sul (UFRGS) sobre Apropriação discente em Ambientes Virtuais de Aprendizagem (REAL, CORBELLINI e SANTOS, 2010). A partir da coleta de dados, a investigação tomou vários contornos envolvendo pesquisa sobre as práticas pedagógicas dos professores em disciplinas a distância e semipresenciais na Universidade (REAL, CORBELLINI, SANTOS e GüNTHER, 2013), a prática pedagógica em um curso de especialização a distância (REAL, CORBELLINI, PALHARES e MARTINS, 2014), a interação dos alunos em vários ambientes de aprendizagem como Moodle, Pbworks, Facebook (REAL, SANTOS e GüNTHER, 2013; REAL, SANTOS e COBERLLINI, 2013), as construções com autorias em Wikis (REAL e CORBELLINI, 2011).

Esta investigação foi realizada na forma de estudo de caso com a finalidade de avaliar as presenças social, cognitiva e de ensino em uma disciplina de graduação.

O estudo de caso, como estratégia de pesquisa, compreende um método que abrange tudo - com a sua lógica de planejamento incorporando abordagens específicas para a coleta de dados e para a análise de dados. Neste sentido, o estudo de caso não é nem uma tática para a coleta de dados nem meramente uma característica do planejamento em si, mas uma estratégia de pesquisa abrangente (YIN, 2010: P. 33).

A disciplina em questão foi Psicologia da Educação: Educação e suas Instituições. Os alunos interagiram a partir dos fóruns do ambiente Moodle. A disciplina é semipresencial e aconteceu no segundo semestre de 2013. Tem como ementa "A análise do status do ensino e da aprendizagem em Instituições Educativas e as modalidades de intervenção utilizadas, bem como as relações internas e externas estabelecidas (grupos de trabalho, serviços, sociedade civil) e sua repercussão no ensino e na aprendizagem. 
Medidas institucionais para a qualificação do ensino e da aprendizagem. Funcionamento institucional: análise e intervenção. Grupos: funcionamento, tipos, abordagem na escola. Educação e Poder". A carga horária era de trinta horas aula sendo que ocorria uma vez por semana, algumas vezes presencial e outras a distância. Nas aulas a distância foram utilizados fóruns de discussão. Na presente investigação são analisados quatro fóruns que ocorreram ao longo da disciplina de acordo com a presença social, cognitiva e de ensino.

Os alunos não são identificados e assinaram o Termo de Consentimento Livre e Esclarecido para que seus dados e postagens pudessem ser utilizados na pesquisa. Os exemplos que são apresentados abaixo (item quatro) conservam a escrita do aluno na sua íntegra.

\section{Presença social, cognitiva e de ensino}

Segundo Mota (2009) através dos princípios norteadores da Comunidade de Inquirição pode se pensar a experiência de aprendizagem em cursos online, pois está se dá por meio da existência e inter-relação das presença de ensino, presença social e presença cognitiva. Segundo o autor citado, o modelo de Garrison, Anderson e Archer (2003) que investiga a partir destas três presenças permite avaliar a qualidade do curso na sua dinâmica considerando a relação entre estudantes, conteúdo e tutores.

A presença social é a forma que o discente encontra para expressar-se socialmente no grupo, trazendo através das suas experiências e vivências parte da sua subjetividade e de seus sentimentos para a interação entre colegas e tutores. Assim o aluno pode projetar suas características individuais na comunidade online, apresentando-se como uma pessoa real e tornando a sua aprendizagem cognitiva uma via mais fácil de ser alcançada. É um colaborador direto da experiência educacional.

A presença cognitiva pode ser considerada a maior instigadora em uma comunidade de investigação, um elemento básico para a avaliação dos discentes que compreende a capacidade dos estudantes em construírem conhecimentos através da reflexão, de debates e da comunicação entre os participantes.

A presença de ensino é o resultado da concepção, facilitação e direcionamento dos processos cognitivos e sociais, fazendo com que os estudantes alcancem resultados de aprendizagem significativa. Tal presença é criada através do papel do professor e/ou do tutor através da partilha de materiais (bibliografias, textos, vídeos, etc.) assim como das instruções diretas fornecidas aos estudantes. É uma presença que se inicia antes do início do curso, na concepção e no planejamento deste pelo professor.

\section{Pensando os fóruns}

Foram realizados quatro fóruns de discussão a partir da plataforma Moodle: (1) Fórum de Recuperação; (2) Discussão sobre Grupos Operativos; (3) Discussão sobre transformações na convivência e (4) Fórum de entrega do trabalho final da disciplina.

4.1 Fórum de Recuperação: fórum direcionado ao recebimento de trabalhos atrasados. Os alunos que participaram, postaram o seu trabalho dirigindo-se especificamente a professora. Além de postar faziam comentários sobre o que estavam postando. Foi um total de vinte e 
nove postagens, dezesseis a fim de recuperar os dois primeiros fóruns trabalhados (fórum 2 e 3), cinco com a finalidade de recuperação da análise do trabalho final da disciplina e oito foram respostas referentes às postagens, tanto da professora como da monitora da disciplina.

As postagens foram classificadas através das presenças de ensino, cognitivas e sociais. Não houve postagem de presença social, quatorze (14) postagens de presença cognitiva, nove (9) presenças de ensino seis (6) postagens contendo tanto a presença social quanto a cognitiva.

Exemplo de presença cognitiva:

Aluna A: Recuperação aula 19/09 - Transformações na convivência

O ser humano é feito de sentimentos. Sendo assim, sempre que conhecemos alguém novo, vamos a um lugar diferente etc, expressamos nossa opinião e o que sentimos em relação a tal.

É difícil se relacionar com o outro, mas é fundamental. Como diz um trecho do texto do Maturana: "(...) conhecimento se dá no momento que estamos interagindo no mundo". E é isso mesmo. Viver em socidade implica em interagir com o próximo. E, nesse "interagir com o próximo", inclui diversas formas de relacionamento.

Em cada "grupo" que fazemos parte, a relação é diferente. Com a família, com colegas de trabalho, com amigos... Cada um tem uma forma peculiar para se conviver. A convivência com o próximo é inevitável, mesmo com pessoas que não "gostamos", com as quais mantemos contato por educação (relação mecânica, como já foi discutido em aula).

Exemplos de presença de ensino:

Monitora: Olá Leonardo, a sua recuperação deve ser referente ao texto de Transformações, do Maturana, consta na lista de recuperações a tua postagem dos grupos operativos, dá uma olhada na aula do dia 19/09.

Professora faz um comentário a partir da postagem do aluno B No grupo operativo não há hierarquia. Deves explicar porque a sala de aula é uma "perfeita instituição"?

Exemplos de presença social e cognitiva:

Aluno B: Professora, confesso que fiquei um pouco confuso em relação a qual das matérias/atividades que deveria ser recuperada aqui que você comentou na ultima aula. Se é sobre a matéria "descrição" ou a parte de "grupos operativos". Portanto estou colocando "contribuições" referentes as duas áreas.Sobre o texto "descrição":

São textos que exemplificam e apresentam os conceitos de o que é uma descrição assim como pode ser realizada. Segundo os textos basicamente descrever é citar detalhes sobre alguma coisa que se vê ou sente, de acordo com o ponto de vista de sua observação, ou seja uma descrição sobre a mesma coisa pode variar de observador para observador. $\mathrm{O}$ ideal de efeito para uma descrição é que quem esteja lendo ou ouvindo a descrição feita por um sujeito chegue mais próximo de entender ou imaginar oque esta sendo descrito.

Descrições podem ser separadas em objetivas e subjetivas, sendo a primeira uma descrição que apresenta caracteristicas físicas do que esta sendo descrito, e a subjetiva apresenta 
caracteristicas da parte emocional relacionada a observação realizada.

Um relato relacionado a psicologia de "grupos operativos": $\mathrm{Na}$ época que trabalhei em uma empresa publica sem ter contrato através de concurso público e ainda assim trabalhar lado a lado com funcionários públicos contratados por concurso. Muitas vezes era difícil a cooperatividade no trabalho por parte de alguns colegas concursados que já estavam la a mais tempo, como se eles possuíssem as informações mantivessem eles nos seus cargos e portanto não compartilhavam parte de seus conhecimentos por receio de perder atividades em determinada área ou cargo. Sendo que eles possuiam um contrato firme com a empresa ao contrário do meu.

4.2 Discussão sobre Grupos Operativos: é proposto aos alunos que tragam exemplos do cotidiano a partir dos conceitos de momentos de grupo operativo, como o fóbico e o contrafóbico, confusional, esquizoide, depressivo ou epileptoide baseado no texto de Bleger (1980). Devem identificar a partir destes momentos reações de grupos em determinadas situações. O fórum contou com um total de 50 postagens, classificadas em: uma (1) presença social, quinze (14) presenças cognitivas, dezenove (19) presenças de ensino e dezesseis (16) presenças cognitivas e sociais.

Exemplos de presença cognitiva:

Aluno D: Acho que os grupos mais presentes são o fóbico e o paranóico. Observou-se estes dois grupos no trabalho e no dia a dia. Colegas de trabalho dão exemplos constantemente de paranóia. Pode-se observar isto dizendo que está sendo perseguido pelo chefe ou algum membro do grupo, mas isto não está acontecendo, apenas é notado por esta pessoa. Quanto a fobia é constante no cotidiano, pois vivemos em vigilia permanente no trânsito, ônibus e em nossas casas pela sensação de insegurança dos dias atuais.

Exemplos de presença social:

Aluno F: Prof ${ }^{a}$ L., ao tentar ler o texto "Grupos Operativos no Ensino" achei o mesmo de difícil compreensão, visto ser carregado de uma série de conceitos com os quais eu nunca havia tomado contato. $\mathrm{O}$ vídeo Grupos Operativos passa de forma muito rápida as definições, ocorrendo dificuldade tb. na sua leitura. Para não colocar informações que não estejam aliadas ao aprendizado, preferi me abster de desenvolver o tema proposto.

Aluno G: Boa noite professora L.

Muito obrigado pela análise gentil e pela sua atenção.

Desejo uma ótima semana para todos!

Exemplos de presença de ensino:

Professora: Pessoal!

Vocês devem escolher um momento de grupo (p. 73), a saber, paranóide, fóbico, contrafóbico, obsessivo, confusional, esquizóide, depressivo, e descrever um momento de grupo que faça parte do cotidiano de vocês exemplificando. Colocar o esquema referencial do grupo, o conteúdo manifesto, o conteúdo latente, a ansiedade, a aprendizagem, etc.

Monitora: Olá pessoal, ainda temos poucas postagens, continuem exemplificando coisas do seu cotidiano, situações diferentes das que aparecem no texto, momentos que 
fazem parte dos grupos que vocês frequentam, não esqueçam que a postagem no fórum é o indicativo da presença em aula.

Exemplos de presença social e cognitiva:

Aluna H: Olá professora!

Devo mencionar que achei esse texto bastante complicado, tive muita dificuldade para compreendê-lo e acredito que isto se deva ao pouco contato (ou quase nenhum contato) com alguns conceitos.

Também fiquei com algumas duvidas do que deveria fazer, mas o que entendi é que deveria descrever algo em minha realidade que esteja de acordo com algum momento mencionado no texto.

Pois bem, acredito que presencio em meu trabalho o momento paranóide, pois o que entendi dele, se trata de considerar perigoso o objeto de conhecimento, e atualmente vem acontecendo isso em uma parte da equipe com a qual trabalho, pois meus colegas (grupo fechado para praticar uma certa atividade) vai receber um menbro novo e estes colegas estão rejeitando e hostilizando este novo colega sem ao menos conhece-lo, acredito que estejam com medo da mudança, medo do novo e de lidar com uma situação que fará com que saiam de sua zona de conforto, para tentar contornar esta situação, minha superior tenta mostra-los o lado bom desta mudança, o crescimento que a equipe vai ter, o conhecimento que se vai adquirir e transmitir ao se integrar um novo membro na equipe.

Não sei se foi assim que pensou esta atividade conosco, mas estou fazendo como entendi.

Abraços.

4.3 Debate a partir do texto "Transformações na convivência” segundo Maturana (REAL, 2007).

Foram realizadas quarenta e uma (41) postagens, sendo cinco (5) postagens de ensino, seis (6) postagens social, dezoito (18) postagens cognitiva, doze (12) postagens social e cognitiva:

Exemplos de presença cognitiva:

Aluna J: A relação hierárquica entre professor e aluno pode ser positiva ou negativa. Pode ser positiva quando o professor, valendo-se do seu conhecimento e da sua experiência, consegue estabelecer na sala de aula situações de aprendizagem, na qual ocorra troca de ideias e negociação de regras que propiciem um ambiente seguro para os alunos desenvolverem autonomia e consigam demonstrar tanto seus talentos como suas dificuldades, para que possam ser trabalhadas e superadas. Mas também pode ser negativa se esta posição hierárquica do professor for imposta através do medo, pois o aluno não se sentirá a vontade para expor seus pensamentos, dificuldades e facilidades.

Em relação à emoção e a linguagem, o professor usa do recurso da linguagem para se comunicar com os seus alunos. Se ele estiver emocionalmente seguro, conseguirá transmitir a informação com eficiência, porém, se isso não ocorrer, o seu estado emocional poderá influenciar negativamente, comprometendo a eficácia do seu trabalho e da construção do conhecimento. Uma outra situação que pode interferir no estado emocional do docente, por exemplo, é quando ele prepara a sua aula com entusiasmo, utilizando recursos diversificados, porém os alunos demonstram desinteresse em aprender e fazem brincadeiras, desestimulando o professor. Nesse caso não serão atingidos os objetivos 
propostos para aquela aula. Esta mesma aula aplicada em outra turma, com alunos dispostos a aprender, possivelmente será produtiva e o professor se sentirá motivado e gratificado.

Exemplos de presença de ensino:

Professora: Pessoal! Este fórum foi bastante proveitoso. As postagens que vocês fizeram demonstraram que entenderam os conceitos principais do texto articulados com o dia a dia. A objetividade entre parênteses foi observada ao longo do fórum, pois alguns alunos conseguiram se posicionar e debater. O fórum também foi implementado com o vídeos e textos sugeridos por colegas. Esta que é a ideia, podermos fazer trocas de experiências, textos, posições, etc. Parabéns a todos!!!

Monitora: Pessoal! O fórum até aqui está muito bom! Os conceitos estão sendo exemplificados com tranquilidade. Parabéns a todos!

Exemplos de presença social:

Aluno M: Mas bah, guri! Gostei. Que baita inspiração! Parabéns, gaudério véio! Bom Feriadão!

Aluno N: Boa noite professora L.

Muito obrigado pela atenção. Só o conheci através de sua disciplina.

Desejo uma ótima semana para todos!

Exemplos de presença social e cognitiva:

Aluno O: A convivência se faz necessária para nós todos. O nosso dia a dia é recheado de momentos de aprendizagem, tanto de caráter observador ou observado. Nossa interação com as pessoas é realizada através da linguagem e da observação. Somos seres interdependentes. Somos clientes num dia e no outro fornecedores. É muito dinâmico este cenário que estamos inseridos, uma entrega de emoções desenvolvidas ininterruptas durante as relações pessoais, deste um "bom dia" até um "boa noite" ditos como introdução de uma conversa ou uma despedida. Somos seres feito para o diálogo. Diálogo de emoções.

Como exemplo para essa introdução, cito o ambiente que vivo quase que diariamente. O transporte coletivo, o trem metropolitano. Pessoas convergem para as estações de manhã, cada um com seus objetivos próprios: trabalhar, estudar e passear. Suas roupas os identificam, estilos de suas vestimentas já podemos dimensionar suas inclinações culturais e desejos. As vezes com bom gosto ao se vestir, mas no entanto, encontro uns com roupas que nada combina. Dentro de um vagão com velocidade, com paradas previstas para cada estação, quase lotação máxima na hora do "pique" , justaposto um ao lado outro, temos: ateus, cristãos, feios e bonitos, jovens, velhos esperando assento, meninas e meninos enviando torpedos em seus celulares, alguns despojados sentados no chão, uma mulher bem maquiada, outras sem nenhuma pintura com cabelos amarrados, casais demonstrando amorosidade e seus beijos rápidos e fortes para despedida iminente. Somos seres com comportamentos distintos, mas estamos ligados diariamente pelas emoções, que são responsáveis pelas mudanças de nosso corpo e cérebro. 
4.4 No fórum de entrega do trabalho final, foram realizados um total de 96 postagens, , sendo: quarenta e cinco (45) referentes a presença de ensino, quarenta e cinco (45) de presença cognitiva, seis (6 )de presença social e cognitiva e nenhuma de presença social.

\section{Considerações finais}

O estudo de caso propiciou a análise qualitativa das presenças de ensino, cognitivas e sociais em quatro fóruns de discussão.

Observou-se que a presença de ensino foi importante para esclarecer dúvidas dos alunos e incentiva-los ao debate, entretanto, apenas no fórum sobre os Grupos Operativos que ela se sobressaiu as outras presenças por necessidade dos alunos terem achado o texto de difícil entendimento. Esta presença, neste momento, foi fundamental para a aprendizagem dos alunos.

A presença cognitiva esteve bastante presente nos fóruns demonstrando a capacidade dos estudantes de refletirem sobre o assunto proposto e a construção de conhecimento sobre cada um dos assuntos abordados.

A partir da análise dos dados foi construída uma categoria que abarcou a presença cognitiva e social a qual foi considerada o auge da aprendizagem dos alunos, pois como a disciplina tem um cunho teórico e prático esta categoria representou a resposta a pergunta do professor articulada com as experiências e vivências dos alunos, ou seja, uma aprendizagem significativa.

\section{REFERÊNCIAS}

BLEGER, José. Temas de Psicologia. Martins Fontes, 1980.

BASSANI, S. Trocas interindividuais no fórum de discussão: um estudo sobre as comunidades de aprendizagem em espaços de educação à distância. Anais dos Workshops do $20^{\circ}$ Simpósio Brasileiro de Informática na Educação (SBIE 2009). UFSC - Santa Catarina.

COBERLLINI, S.; REAL, L. C.. Educação Semipresencial: “espaços e tempos complementares?". Anais do 23. ' Simpósio Brasileiro de Informática na Educação (SBIE 2012), Rio de Janeiro/RJ, 26 a 30 de novembro de 2012. http://www.br-ie.org/pub/index.php/sbie/index

DAMACENO, H. L. C.; BONILLA, M. H.; ARAÚJO, M. M. S. Formação colaborativa entre professores: o caso Prouca-Bahia. Anais dos Workshops do 23. ${ }^{\circ}$ Simpósio Brasileiro de Informática na Educação (CBIE 2012), Rio de Janeiro/RJ, 26 a 30 de novembro de 2012.

KOCH, S. H. S.; PASSERINO, L.M. Processos Metacognitivos com o uso das TIC. Anais do XXII SBIE - XVII WIE. Aracaju, 2011. 
GARRISON, R; ANDERSON, T; ARCHER, W. Critical Inquiry in a text-based environment: Computer conferencing in higher education. Internet and Higher Education, 11(2), 2000. p 1-14.

GARRISON, R; ANDERSON, T. eLearning in the 21st Century: A Framework for Research and Practice. London \& New York: RoutledgeFalmer, 2003.

LONGHI; BEHAR; BERCHT; SIMONATO. Investigando a subjetividade afetiva na comunicação assíncrona de ambientes virtuais de aprendizagem. Anais dos Workshops do $20^{\circ}$ Simpósio Brasileiro de Informática na Educação (SBIE 2009). UFSC - Santa Catarina.

MOTTA, José Da Web 2.0 ao e-Learning 2.0: Aprender na Rede. Dissertação de Mestrado, Versão Online, Universidade Aberta, 2009.

REAL, Luciane Magalhães Corte. Aprendizagem amorosa na interface Escola, Projetos de Aprendizagem e Tecnologias Digitais. Tese de Doutorado, PGIE/UFRGS, 2007.

REAL, L. M. C.; CORBELLINI, S. Proposta Cooperativa em Curso de Graduação a Distância Construída em WIKIs. Sexta Conferencia de Objetos de Aprendizaje. Uy, 2011.

REAL e PICETTI. Fórum de discussão: espaço de possibilidades de transformações na convivência. Anais do Segundo MoodleMootUY, Montevideo, Uruguay, 2012.

REAL, CORBELLINI, SANTOS e GüNTHER. Wikis: redes virtuais potencializando o aprendizado de alunos de graduação. V Seminário Internacional de Educação a Distância, UFMG, 2013.

REAL, SANTOS e GüNTHER. O uso de um espaço virtual desafiando a escrita coletiva em uma Universidade Pública. In: XII Congreso Latinoamericano para el Desarrollo de la Lectura y la Escritura; IV Foro Iberoamericano de Literacidad y Aprendizaje, 2013, Puebla, México. Memoria de Trabajos del XII CLDLyE y IV FILA. Puebla, México: Benemérita Universidad Autónoma de Puebla, 2013. p. 1039-1046.

REAL, L. C.; SANTOS, G. S.; COBERLLINI, S. Mapeando apropriações docentes e discentes em Ambientes Virtuais de Aprendizagem. ESUD, 2013 - X Congresso Brasileiro de Ensino Superior a Distância, UNIREDE, Belém/Pa, 11 a 13 de junho de 2013. http://www.aedi.ufpa.br/esud/trabalhos-oral.html

REAL; CORBELLINI; PALHARES e MARTINS. O currículo em construção em um curso de especialização online. Anais do Simpósio Internacional de Educação a Distância, São Carlos, 2014.

YIN, R. K. Estudo de caso: planejamento e métodos. 4 Ed. Porto Alegre: Bookman, 2010. 